\title{
Alleviation of aluminum in acidic soils and its effect on growth of hybrid and clonal oil palm seedlings.
}

\begin{abstract}
Aluminum ( $\mathrm{Al}$ ) toxicity is an important factor in limiting crop production. The present study examined the $\mathrm{Al}$ alleviation effects on the growth of hybrid (breeding) and clonal (tissue culture) of $\mathrm{D} \times \mathrm{P}$ oil palm seedlings. The experiment was performed using calcium carbonate $(\mathrm{CaCO} 3)$, and ground magnesium limestone (GML) and magnesium carbonate $(\mathrm{MgCO} 3)$ as soil-amendments at different rates in Colombia and Malaysia, respectively. The effects of the treatments were evaluated monthly on vegetative variables and visual symptoms. Chlorophyll concentrations were recorded in Malaysia at the fifth month growing stage. The different amendments improved the soil fertility and it was reflected on better performance of shoot and root growth. The chlorophyll content in the frond number 3 for both materials enhanced significantly when Al saturation was low $(0-30 \%)$. The results from the experiment revealed the importance of neutralization of $\mathrm{Al}$ in reducing its toxicity in oil palm.
\end{abstract}

Keyword: Chlorophyll concentration; Clonal; Oil palm seedlings; Plant growth; Soil acidity; Soil amendments. 